\title{
DINÂMICA FAMILIAR: PERCEPÇÃO DE FAMÍLIAS DE SOBREVIVENTES DE CÂNCER DE MAMA
}

\section{Family dynamics: perceptions of breast cancer survivor's families. Dinámica familiar: percepción de familias de sobrevivientes de cancer de mama}

\author{
Raquel Gabrielli Biffi ${ }^{1}$
}

Marli Vilela Mamede ${ }^{2}$

\begin{abstract}
RESUMO
0 estudo teve como objetivo identificar as percepções de familiares sobre a dinâmica de suas famílias após o câncer de mama em um dos seus membros. Estudo de abordagem qualitativa que tomou como referencial teórico o modelo de funcionamento familiar saudável proposto por Barnhill (1979). Participaram 23 familiares constituintes de 10 famílias. Os dados foram coletados, no período de maio a junho de 2002, por meio de entrevistas, e submetidos à análise de conteúdo. Os resultados revelaram aspectos positivos na dinâmica das famílias. A percepção dos processos de identidade, através da individuação e mutualidade, favoreceram a compreensão da dinâmica familiar. Os achados mostraram que o câncer de mama tem a capacidade de provocar alterações na família, e esta se utilizou dos potenciais de cada membro em particular na busca da estabilidade familiar.
\end{abstract}

Palavras-chave: Família. Neoplasias da Mama. Saúde da Mulher.

\begin{abstract}
The aim of this study was to identify the family members' perceptions of their family dynamics, after breast cancer in one of its members. The study used a qualitative approach based on the theoretical model of healthy family function proposed by Barnhill (1979). There were 23 participants from 10 families. The data was collected by means of interviews and subsequent analysis of content that revealed positive aspects in the family dynamics in which the processes of identity, through individuality and mutuality favored the understanding of the family dynamics. The findings showed that breast cancer has the capacity to provoke changes in the family, which enables them to use the potential of each member in the search for stability.
\end{abstract}

Keywords: Family. Breast Neoplasms. Woman's health.

\section{Resumen}

El estudio objetiva identificar las percepciones de familiares sobre la dinámica de sus familias, con cáncer de mama en uno de sus miembros. Estudio de abordaje cualitativo que tomó como referencial teórico el modelo de funcionamiento familiar saludable de Barnhill (1979). Participaron 23 familiares constituyentes de 10 familias. Los datos fueron obtenidos mediante entrevistas y sometidos a análisis de contenido. Los resultados revelaron aspectos positivos en la dinámica de las familias. La percepción de los procesos de identidad, a través de la individualización y mutualidad, favoreció la comprensión de la dinámica familiar. Según los resultados, el cáncer de mama tiene la capacidad de provocar alteraciones en la familia; por otro lado, éstas se utilizaron de los potenciales de cada miembro, en particular, en la búsqueda de la estabilidad familiar.

Palabras clave:Familia. Neoplasias de la mama. Salud de la mujer.

'Professora Titular do Departamento de Enfermagem do Centro Universitário Barão de Mauá Ribeirão Preto-SP. Brasil. Email: gabriellibiffi@yahoo.com.br 2Professora Titular do Departamento Materno Infantil em Saúde Pública da Escola de Enfermagem Ribeirão Preto - Universidade de São Paulo-USP. Brasil. Email: mavima@eerp.usp.br 


\section{INTRODUCÃO}

Muitos dos sentimentos apresentados pelas mulheres com câncer de mama ainda são obscuros e repletos de lacunas, assim o espaço de enfrentamento dessa situação geralmente é transformado num problema para a mulher e família que demanda atuação dos profissionais da saúde.

Enfrentar o câncer demanda mobilização de várias pessoas, e a família tem se mostrado importante na configuração dessa rede de suporte social, principalmente porque a doença não é problema apenas do indivíduo, mas também dos seus familiares, amigos, enfim das pessoas do seu convívio ${ }^{1,2,3,4}$.

A confirmação do diagnóstico de câncer de mama leva a mulher e a família a questionarem sobre difíceis decisões e enfrentamentos, a analisarem a viabilidade de amenizar o sofrimento de todos, em especial de quem vivencia a doença. Costuma ser comum observar na unidade familiar dificuldades para o estabelecimento de condutas e comportamentos que promovam o equilíbrio familiar, portanto o grupo familiar necessita estar atento e reflexivo quanto a este processo e identificar as várias situações conflitantes expostas pelos seus membros para que não venham emergir discórdias irreparáveis no futuro ${ }^{5}$.

Uma forma de assistir a família é ajudá-la a desenvolver novas maneiras de interação entre seus membros, pois à medida que alteram suas percepções sobre a enfermidade, seus comportamentos poderão mudar e facilitar o processo de adaptação à nova condição. Acrescem as autoras que uma das responsabilidades da enfermeira é facilitar o processo de mudanças no funcionamento familiar e desta forma colaborar com cada família ${ }^{6}$.
A avaliação das fortalezas e fragilidades presentes no funcionamento familiar é um dos desafios da enfermeira que assiste a mulher com câncer de mama, pois implica um tipo de avaliação que é oposta à avaliação individual e para tanto requer do profissional habilidades adicionais e grande esforço devido à complexidade que existe no interior dos relacionamentos familiares.

Portanto, incorporar a família na unidade de cuidado à mulher mastectomizada é urgente e relevante. Para 0 atendimento dessa necessidade, se faz necessário compreender como se processa a dinâmica das famílias de mulheres sobreviventes ao câncer de mama, e então identificar as demandas de atenção para a unidade familiar.

Nesta direção, o presente trabalho teve como finalidade responder à seguinte questão: Como os diversos membros da família de mulheres acometidas pelo câncer de mama percebem a dinâmica de suas famílias após a chegada da doença?

0 objetivo foi identificar as percepções de familiares sobre a dinâmica de suas famílias após o surgimento do câncer de mama em um dos seus membros.

\section{PERCURSO METODOLÓGICO}

Estudo de abordagem qualitativa que tomou como referencial teórico o modelo de funcionamento familiar saudável ${ }^{7} 0$ modelo de dinâmica familiar fundamenta-se na abordagem da teoria de sistemas e é dividido em oito dimensões bipolares que são agrupadas em quatro processos familiares básicos. No quadro abaixo, são descritos os processos e significados de cada uma das dimensões da teoria do sistema familiar saudável ${ }^{7}$

Quadro 1: Descrição das oito dimensões básicas do funcionamento familiar saudável proposto por Barnhill.

\begin{tabular}{|c|c|c|}
\hline \multirow{4}{*}{$\begin{array}{l}\text { Processo de } \\
\text { Identidade }\end{array}$} & Individuação & Simbiose \\
\hline & $\begin{array}{l}\text { Referem-se à independência de } \\
\text { pensamentos, sentimentos e julgamentos } \\
\text { dos membros familiares. Identidade e } \\
\text { limites do "self". }\end{array}$ & $\begin{array}{l}\text { Refere-se a limites precariamente } \\
\text { delineados do "self", a uma identidade } \\
\text { dependente dos outros, à simbiose e à } \\
\text { fusão do "self" compartilhado. }\end{array}$ \\
\hline & Mutualidade & Isolamento \\
\hline & $\begin{array}{l}\text { Proximidade emocional, intimidade, } \\
\text { possível somente entre indivíduos com } \\
\text { identidades claramente definidas. }\end{array}$ & $\begin{array}{l}\text { Alienação ou ao desengajamento dos } \\
\text { outros. }\end{array}$ \\
\hline \multirow{4}{*}{ Alteração } & Flexibilidade & Rigidez \\
\hline & $\begin{array}{l}\text { Capacidade de ser ajustável e flexível } \\
\text { em resposta a condições variadas e aos } \\
\text { processos de mudanças. }\end{array}$ & $\begin{array}{l}\text { Falta de flexibilidade, à responsividade } \\
\text { inadequada e malsucedida e a } \\
\text { circunstâncias variáveis estereotipadas e } \\
\text { repetitivas. }\end{array}$ \\
\hline & Estabilidade & Desorganização \\
\hline & $\begin{array}{l}\text { Consistência, responsabilidade e } \\
\text { segurança nas interações familiares. }\end{array}$ & $\begin{array}{l}\text { Falta de estabilidade ou de consistência } \\
\text { nas relações familiares. }\end{array}$ \\
\hline \multirow{4}{*}{$\begin{array}{l}\text { Processo de } \\
\text { Informação }\end{array}$} & Comunicação Clara & Comunicação Distorcida \\
\hline & $\begin{array}{l}\text { Troca de informações claras e bem- } \\
\text { sucedidas entre os membros da família }\end{array}$ & $\begin{array}{lllll}\begin{array}{l}\text { Intercâmbio vago ou confuso de } \\
\text { informações }\end{array} & & & \\
\end{array}$ \\
\hline & Percepção clara & Percepção confusa \\
\hline & $\begin{array}{l}\text { Consciência não-distorcida de si próprio } \\
\text { e dos outros. }\end{array}$ & Percepções distorcidas dos outros. \\
\hline \multirow{4}{*}{$\begin{array}{l}\text { Estruturação } \\
\text { de Papéis }\end{array}$} & Reciprocidade de papéis & Conflito de papéis \\
\hline & $\begin{array}{l}\text { Padrões ou sequências de } \\
\text { comportamentos de acordos mútuos em } \\
\text { que o indivíduo complementa o papel } \\
\text { de um parceiro. }\end{array}$ & $\begin{array}{l}\text { Falta de acordos claros sobre a } \\
\text { complementaridade comportamental entre } \\
\text { os membros da família. }\end{array}$ \\
\hline & Limites claros entre gerações & Limites difusos ou perturbados \\
\hline & $\begin{array}{l}\text { Reciprocidade de papéis entre os } \\
\text { membros da família. }\end{array}$ & $\begin{array}{l}\text { Falta de clareza nos limites entre as } \\
\text { gerações. }\end{array}$ \\
\hline
\end{tabular}




\section{Sujeito}

Os sujeitos da pesquisa foram dez famílias de mulheres com câncer de mama, que participavam do Núcleo de Ensino Pesquisa e Assistência na Reabilitação de Mastectomizadas, "Rema", da Escola de Enfermagem Ribeirão Preto Universidade de São Paulo USP.

Os familiares foram incluídos no estudo se atendessem aos seguintes critérios: ser familiar de mulher com câncer mama há pelo menos três meses e residente no município de Ribeirão Preto ou localidades próximas até $50 \mathrm{~km}$ de distância; ter residência fixa na casa da mulher; e ter mais de 18 anos de idade. Participaram do estudo 23 familiares.

\section{Instrumento de Coleta de Dados}

Utilizou-se um roteiro de entrevista semi-estruturada, com perguntas abertas, previamente elaboradas, as quais direcionavam para o entendimento do funcionamento da família após o câncer de mama. Para validação do instrumento, foram realizadas entrevistas com quatro mulheres com câncer de mama e 13 familiares, os quais não foram incluídos no estudo.

\section{Procedimentos}

Após a confirmação da participação dos familiares na pesquisa, foram realizadas entrevistas individuais, na data $\mathrm{e}$ local convenientes para cada um deles. A coleta de dados somente foi iniciada após aprovação no Comitê de Ética em Pesquisa e aceitação dos sujeitos em participar e assinatura do Termo de Consentimento Pós-Informado. As entrevistas foram gravadas e transcritas posteriormente, mediante a permissão dos participantes.

Os depoimentos dos familiares foram submetidos à análise de conteúdo, buscando identificar unidades temáticas que representavam as dimensões do modelo de dinâmica familiar? As dimensões relacionadas à percepção clara e percepção confusa ou distorcida não foram utilizadas no presente estudo por entendermos que estas funcionam como pré-requisito para identificar a qualidade da comunicação entre os membros familiares.

0 processo de categorização e identificação de unidades temáticas seguiu os procedimentos descritos por Bardin ${ }^{8}$

Para assegurar maior confiabilidade e validação ao processo de identificação de temas relacionados às dimensões do modelo de dinâmica familiar ${ }^{7}$ nos conteúdos das entrevistas, estes foram submetidos à validação de construto por três juízes, sendo um pesquisador experiente na área e dois doutorandos e especialistas no atendimento à saúde da mulher e suas famílias. A validade de construto pode ser definida como a adequação da definição operacional das variáveis que mostra que a medida empregada realmente mede o construto que pretende medir 9 .

Mediante apresentação aos juizes dos conceitos das dimensões do modelo teórico e de um conjunto de recortes das entrevistas, foi solicitada a eles a classificação dos mesmos conforme as dimensões do modelo. Após tais procedimentos, verificou-se a concordância entre eles e as autoras. Quando havia discordância da classificação feita pelas autoras com mais de um juiz, o recorte era descartado.

\section{Aspectos éticos}

A pesquisa foi submetida à avaliação e aprovação pelo Comitê de Ética em Pesquisa da Escola de Enfermagem de Ribeirão Preto-USP, atendendo as Normas Regulamentares para desenvolvimento de pesquisas com seres humanos de acordo com a Resolução 196/96 do Conselho Nacional de Saúde do Ministério da Saúde.

\section{ANÁLISE E DISCUSSÃO DOS DADOS}

\section{Caracterização das famílias}

A configuração dos participantes das dez famílias estudadas apresenta-se da seguinte forma: nove filhas, cinco filhos, sete parceiros, uma tia e uma sobrinha, perfazendo um total de 23 indivíduos. A faixa etária dos membros familiares variou de 18 a 85 anos, assim desmembrada: a idade das filhas variou de 19 a 37 anos; dos filhos, de 18 a 35 anos; dos maridos, de 46 a 62; os outros eram uma tia de 85 anos e uma sobrinha de 20 de idade.

Quanto ao grau de escolaridade das filhas, quatro haviam cursado o ensino médio completo; duas, o superior completo; e três, superior incompleto. Com relação aos filhos, dois completaram o ensino médio; dois, o nível superior, estando um deles fazendo pós-graduação, e o outro concluiu o curso técnico. Três maridos tinham o ensino fundamental incompleto; dois completaram o ensino médio; um, o ensino superior, e apenas um era semianalfabeto. Os outros elementos familiares: a tia não completou o ensino fundamental e a sobrinha não completou o ensino médio.

De acordo com a Classificação Brasileira de Ocupações $(\mathrm{CBO})^{10}$, os membros da família exerciam as seguintes ocupações: quatro trabalhavam em profissões científicas, técnicas e assemelhados (advogado, professor universitário, fisioterapeuta e economista); três eram trabalhadores de serviços administrativos e assemelhados (diretor administrativo, auxiliar administrativo, processador de dados); outros quatro elementos exerciam atividades como trabalho em comércio e assemelhados (dois recepcionistas, dois representantes comercial); outros três eram trabalhadores de serviços de turismo, hospedagem, servente, embelezamento, segurança e assemelhados (porteiro, auxiliar de enfermagem e servente). Quanto aos parceiros conjugais, cinco eram trabalhadores de produção industrial (operadores máquinas, condutores de veículos e assemelhados), exercendo as funções de operador de máquinas, abastecedor de ônibus motorista e mecânico de manutenção. Duas filhas eram estudantes; e os outros elementos: a sobrinha estava desempregada no momento e a tia era e aposentada. 


\section{Estrutura familiar e percepção da dinâmica familiar após o câncer de mama}

Apresentar cada uma das famílias que participou do presente estudo foi a forma encontrada para romper a tendência de isolar conceitualmente o indivíduo de sua família, tornando praticamente impossível a previsão do curso do processo de reabilitação da mulher com câncer de mama. Conforme explica Ackerman ${ }^{11}$, a unidade adequada de previsão não pode ser a pessoa sozinha, mas deve ser o ambiente-família como uma unidade integrada.

Na família 1, composta por seis membros, mulher, marido, três filhos e um neto, a mulher com câncer de mama, de 52 anos, não completou o ensino médio e tinha como ocupação atividades do lar. Esta se submeteu à cirurgia há um ano e seis meses por câncer de mama, tipo quadrantectomia, e à radioterapia.

De acordo com as dimensões de funcionamento familiar ${ }^{7}$, os membros da família 1 (Quadro 2) percebiam, dentre os processos de identidade, características de individuação, os aspectos mais positivos em relação a uma dinâmica familiar saudável, conforme mostra o relato.

Minha filha é que mais apoia, porque ela trabalha no hospital, tem mais conhecimento. Ela sabe da doença, quase sempre é ela que vai ao médico. $E$ ela quem toma mais a iniciativa. F1

No século XX, a família foi caracterizada, sobretudo, pela construção de uma lógica de grupo centrada no amor e na afeição. Essa família, quase sempre tomada como referência nos discursos sobre a idade de ouro da família, é um grupo regulado pelo amor, do qual os adultos estão a serviço, principalmente das crianças. No entanto, a família atual, ainda com algumas características antigas, se distingue da precedente pelo peso maior dado ao processo de "individuação". 0 elemento central não é mais o grupo reunido, são os membros que a compõem; a família se transforma, então, em espaço privado a serviço dos indivíduos. Acreditar que se esconde no fundo de si mesma uma identidade pessoal, um verdadeiro "eu", faz com que esse mito de interioridade vá se constituindo de forma lenta até se tornar uma evidência normativa para cada um de nós, à qual se juntou um outro ser imperativo, o ser autônomo. Essa procura de si mesmo não se traduz, prioritariamente, em um narcisismo; ao contrário, ela exige uma atenção do olhar dos outros. Inversamente, o termo individualismo leva a crer que o indivíduo precisa, para tornarse ele mesmo, do olhar das pessoas a que ele atribui importância ${ }^{12}$.

A individuação e mutualidade entre todos os membros são sinais relevantes nessa dinâmica familiar, apesar de sinais de isolamento e comportamento simbiótico percebidos em alguns membros. 0 comportamento simbiótico foi expresso pelo parceiro, revelando ausência de limites entre o ego da parceira e o dele mesmo.
Não conversei sobre as dificuldades do câncer, a gente vai fazendo conforme vai acontecendo, não conversei nada..., para superar tenho levado mais ou menos em consideração da doença dela..., a gente não tem muita experiência com isso. F1

Os depoimentos dos familiares possibilitaram a identificação de aspectos positivos nas dimensões relacionadas tanto à individuação como à mutualidade, flexibilidade, estabilidade, comunicação clara e reciprocidade de papéis. No entanto, percebemos também sinais de isolamento quando o parceiro e a filha indicaram os filhos como membros que menos apoiaram a mãe.

Os dois homens são os que menos apoiaram, não esquentam a cabeça com nada. 0 mais isolado e desligado é o meu irmão mais velho, não sei o porquê, mais é ele. F1

Um dos filhos da família 1, apesar de apresentar características de comportamentos mútuos entre os membros da família, revelou características de esquiva e necessidade de ajuda, conforme segue o depoimento abaixo:

Eu sempre procureiconversar com os meus colegas de serviço para superar as dificuldades que o câncer de mama da minha mãe trouxe, eu sou muito apegado com eles, eu sou mais apegado com eles do que com minha mãe e meu pai. Procurei fazer alguma coisa assim que eles me falavam. Foi com meus colegas que eu procurei apoio. F1

Percebemos sinais de desorganização nas falas dos dois filhos, mostrando dificuldades ao vivenciarem a nova condição de saúde da mãe:

Eu tive dificuldade para lidar com o diagnóstico do câncer principalmente na parte emocional. Eu trabalho como digitador, eu estava digitando errado. O meu chefe me chamou para saber o que estava acontecendo..., expliquei que estava acontecendo. $\mathrm{Na}$ escola eu percebi que eu piorei meu rendimento e nas notas. F1

0 estágio inicial da doença, a fase de tratamento e das reações da família são as fases mais estressantes, pelos sinais de desorganização e isolamento, conforme identificado na família 1. Os familiares que vivenciam o câncer de mama frequentemente experimentam considerável sofrimento durante o período que se deparam com a possibilidade do diagnóstico do câncer e a realidade do tratamento ${ }^{4}$.

Quanto aos aspectos relacionados à capacidade de promoção ou realização de mudanças, observamos traços de condutas resistentes às mudanças, revelando certa desorganização, embora traços de flexibilidade, estabilidade e 
comunicação clara estivessem presentes na fala de alguns familiares. A estruturação de papéis, revelada nos depoimentos, mostrou uma positiva reciprocidade, ao redefinir as atribuiç̃̃es e tarefas de cada um na constelação familiar.

Na família 2, composta por três membros: mulher, marido e enteado, a mulher com câncer de mama, de 46 anos de idade, cursara o ensino superior completo, era enfermeira. Submeteuse à cirurgia por câncer de mama, tipo Patey, à quimioterapia e à radioterapia. Estava com um ano e sete meses de pósoperatório.

$\mathrm{Na}$ análise dos depoimentos, pudemos identificar que 0 marido e o enteado demonstraram sinais de uma dinâmica familiar saudável, quadro 2, pois evidenciava ser um grupo integrado, revelando características como: individuação, mutualidade, flexibilidade, estabilidade e comunicação clara, conforme relatos:

Eu tenho feito tudo para poder dar o maior suporte pra ela. Eu percebi que já fazia um tempo que ela não bebia água, e eu pego um copo comágua e levo para ela. São pequenas coisas, pequenos atos que são grandes e fortalecem para que ela consiga tocar a vida sem ficar deprimida. F2

E aí pai, como está o relacionamento de vocês?Porque é uma coisa que eu nunca tinha perguntado pra ele, eu não sabia se de repente eu poderia estar ajudando de alguma forma. A gente conversou, foi bem legal. F2

Da mesma forma, os depoimentos revelaram um clima interpessoal adequado entre os membros, caracterizado pela participação ativa na comunidade, e no contato com amigos e demais membros da família extensiva.

$\mathrm{Na}$ familia 3, composta por quatro membros: mulher, marido e dois filhos, a mulher com câncer de mama, de 47 anos de idade, não completou o ensino fundamental, e sua ocupação eram as atividades do lar. Submeteu-se à cirurgia por câncer de mama, tipo nodulectomia, quimioterapia e radioterapia. Estava com dois anos e sete meses de pós-operatório.

$\mathrm{Na}$ análise dos depoimentos dos membros familiares, aparentou ser um grupo com traços de isolamento, rigidez, desorganização e comunicação distorcida.

Para superar as dificuldades que o câncer trouxe, eu trabalho, fumo, tomo cerveja pra esquecer; tomando cerveja, a gente até esquece, pelo menos a gente sabe que é uma coisa boa, pelo menos a gente relaxa um pouco. F3

0 estudo ${ }^{3}$ mostra que as famílias que apresentam maior conflito em seu funcionamento diante do câncer de mama também apresentam baixo nível de coesão e expressividade, comportamento independente entre os membros da família, desinteresse pelos problemas provocados pela doença e, ainda, falta de desejo de compartilhar sentimentos.

Por outro lado, em alguns momentos foi possível identificar que o marido revelou aspectos positivos na dinâmica familiar, como reciprocidade de papéis nas rotinas domésticas.

Os parceiros têm uma importante participação no processo de reabilitação da mulher com câncer de mama, demonstrando sua flexibilidade em ajustar horários e padrões de comportamento para acompanhar as mulheres nas consultas médicas e tratamentos e para auxiliá-las com as tarefas domésticas. As mulheres reconhecem a demonstração de afeto dos seus parceiros e a preocupação destes com ela, ingredientes que se constituem em conteúdos e qualidade de suporte social ${ }^{13}$.

Eu tenho que entender ela por tudo que passou, procuro sempre falar para ela que a amo muito, não que eu a amasse menos antes, mas demonstrar mais depois, também a ajudando em casa, indo às consultas médicas F3

Percebemos que o clima interpessoal não se apresentou de forma tão adequada, pois à medida que os membros (marido e filha) utilizaram os recursos para auxiliar a mulher nessa nova condição de saúde, procuravam alternativas para esquivar do problema. 0 marido buscou refúgio para seus problemas na bebida e no cigarro, ausentando-se da casa ou evitando falar no assunto, prejudicando os potenciais de crescimento da família e também o processo de adaptação e reabilitação da cliente.

$\mathrm{Na}$ família 4, composta por mulher, marido e dois filhos, a mulher com câncer de mama tinha 63 anos de idade, cursou o ensino superior e era professora aposentada. Submeteu-se à cirurgia por câncer de mama, tipo Patey, à quimioterapia e à radioterapia. Estava com oito anos de pós-operatório.

A análise dos depoimentos dos familiares mostrou uma dinâmica familiar saudável, Quadro 2, pois tanto o parceiro como a filha revelaram em seus relatos traços de mutualidade, flexibilidade e estabilidade no oferecimento de apoio à cliente portadora de câncer, conforme transcrições abaixo:
A familia se uniu e eu pude observar que amigos, parentes também se uniram, então eu acho que com isso houve uma união maior entre nós, o laço familiar já era forte e dessa vez amarrou mesmo, fechou mesmo. F4

A ajuda da família e de amigos mostra que o câncer de mama e seu tratamento geram a mobilização de um sistema social amplo ao redor da mulher, que pode ser muito útil neste momento de crise ${ }^{14}$.

É importante ressaltar que a filha mostrou também traços de individuação, embora o pai e a filha deixassem transparecer alguns sinais de isolamento diante da nova condição de saúde de sua parceira e comunicação distorcida ou confusa. 
Eu não conversava com ninguém sobre o câncer...,guardava para mim, porque eu tenho uma filha, e eu não queria preocupar ninguém. F4

Às vezes eu chegava de madrugada, ela estava sentada no sofá chorando, eu não falava nada. Era o momento de ela desabafar, pôr pra fora, talvez eu indo lá pudesse atrapalhar, ia para a cama e chorava também. F4

A pesquisa ${ }^{15}$ aponta que os maridos em certos momentos se sentem desamparados e sozinhos diante da situação vivenciada pela sua parceira e adotam atitude protetora com relação às suas esposas, não compartilhando com elas seus próprios sentimentos e preocupações. Esta atitude muitas vezes conduz ao aumento da ansiedade e sobrecarga deles. Apesar de os esposos se manterem presentes e apoiadores, eles vêem como necessário assumir uma postura de força que nega seus próprios sentimentos e restringe a intimidade entre os membros do casal.

Os familiares revelaram possuir uma capacidade fluida, elástica, de se adaptar às mudanças, além de mostrar coesão e integração interna. A doença propiciou o crescimento dos membros individualmente e do grupo como um todo.

A família 5 era composta por oito membros, mulher, seis filhos e uma tia, porém em sua casa residiam somente um filho e uma tia. A mulher com câncer de mama, de 61 anos de idade, separada, completou o ensino superior, era professora aposentada. Submeteu-se à cirurgia por câncer de mama, tipo Madden, e à quimioterapia. Estava com um ano e dois meses de pós-operatório.

Os relatos dos entrevistados revelaram que as relações familiares mostravam uma dinâmica familiar caracterizada por mutualidade, estabilidade e comunicação clara (Quadro 2), porém a comunicação clara foi verificada apenas com os outros membros da família, entre os irmãos, e em nenhum momento houve comunicação clara deles diretamente com a mãe.

Quando tinha alguma notícia a respeito de exames relacionados com o câncer, a gente sentava e conversava, nós os irmãos, com ela era muito pouco. F5

A dificuldade da comunicação clara a respeito do câncer com a portadora pode estar relacionada com a negação da doença como forma de se defrontar com a morte. Nesse sentido, os familiares podem não aceitar que a paciente conte suas angústias e seus temores a respeito da doença, com a desculpa de que querem Ihe dar ânimo e evitar que pense "bobagens". Porém, por baixo do manto de proteção de um ente querido, muitas vezes se oculta o próprio temor do familiar de reconhecer que qualquer um pode ser acometido pelo câncer ${ }^{16}$.
Vale ressaltar que o grupo familiar era integrado também com os elementos que não moravam na mesma casa, irmãos e irmãs, e no enfrentamento do câncer da mãe a estabilidade foi oferecida principalmente por esses membros, pois parece que, pelo fato de serem profissionais da saúde, as responsabilidades foram delegadas a eles.

Bem, na época que ela teve o câncer, na verdade eu não fui um dos filhos que ficaram mais envolvidos com a situação, mesmo porque eu tenho muitos irmãos médicos e eles cuidaram de quase tudo. F5

0 isolamento e a desorganização foram perceptíveis nos relatos do filho, mostrando a falta de responsabilidade, como elemento de pouco apoio no enfrentamento do câncer de mama da mãe.

Acredito que eu dou pouco apoio, mesmo porque são tantos irmãos que acaba sobrando pouco pra mim. F5

A tia identificou na interação familiar características de mutualidade entre eles, pois se sentia segura e protegida convivendo com a família, mas como elemento de apoio para o enfrentamento de mudanças na sua rotina revelou sinais de rigidez, isolamento, simbiose e comunicação distorcida.

De uma forma geral, a família 5 revelou um clima interpessoal positivo entre os membros, sinais de forte estabilidade, satisfazendo os potenciais de crescimento de todos e, em especial, da cliente com câncer de mama.

Na família 6, composta por três membros: mulher, marido e filha, a mulher com câncer de mama tinha 51 anos de idade, não completou o ensino fundamental, na época da entrevista estava aposentada. Submeteu-se à cirurgia por câncer de mama, realizando quadrantectomia, quimioterapia e radioterapia. Estava com oito anos e um mês de pós-operatório eno momento fazia tratamento quimioterápico por causa de metástase mamária.

Os depoimentos dos familiares revelaram ser um grupo, parceiro e filha, que apresentava comportamento coeso, responsável e com proximidade emocional nas interações familiares. Demonstrou individuação, mutualidade, estabilidade e comunicação clara na sua rotina, Quadro 2; entretanto, na época da suspeita do diagnóstico, conforme os relatos, sinais de desorganização e comunicação distorcida no enfrentamento das mudanças e processamento de novas informaç̃es estiveram presentes.

Meu apoio... .Nós não entramos em detalhes sobre a doença e eu não discuto quando fico sabendo de algum caso, também não entro em detalhes com ela, mas ficamos sempre juntos. Então o apoio que eu dou é viver como eu vivia antes com ela..., não mudei nada. F6 
Em alguns momentos, conforme relato da família 6, a demonstração de afeto e apoio ocorre por meio de uma "compreensão silenciosa", que permite aos familiares, principalmente os parceiros, entender as mudanças e as alterações nas emoções de suas parceiras, aceitando a situação sem qualquer questionamento ${ }^{13}$.

Observamos reciprocidade de papéis e flexibilidade na dinâmica familiar, oferecimento de apoio do parceiro à parceira, proporcionando um acordo mútuo sobre os padrões de comportamento e enfrentamento de mudanças, de modo que a dinâmica familiar desse grupo revelou traços que favoreceram o crescimento de cada membro em particular.

A família 7 era composta por seis membros: mulher, marido e quatro filhos, porém na casa moram apenas uma filha e 0 marido. A mulher com câncer de mama, com 54 anos de idade, não completou o ensino fundamental, tendo como ocupação as atividades do lar, de costureira e comerciante. Submeteu-se à cirurgia por câncer de mama, tipo Patey, à quimioterapia e à radioterapia. Estava com oito anos e seis meses de pósoperatório, no momento fazia tratamento quimioterápico devido à metástase óssea.

$\mathrm{Na}$ análise dos depoimentos dos familiares, o parceiro apresentou características de comportamento de isolamento, rigidez, desorganização e comunicação distorcida no suporte à parceira com relação ao enfrentamento do câncer de mama (Quadro 2).

Nesse sentido, segundo relatos da filha, as atitudes do pai estavam ocasionando nela limites difusos ou perturbados e comunicação distorcida, interferindo na dinâmica familiar saudável:

O meu pai dá menos apoio para ela, ele não pergunta o que ela tem, se ela está com dor ou não, e ela sofre muito com isso também. F7

A minha mãe fala com a gente...e ela sofre muito com isso; "Puxa ele não está ligando", mas é o jeito dele, ele é muito desligado. F7

As famílias que apresentam maior conflito em seu funcionamento diante do câncer de mama também apresentam baixo nível de coesão e expressividade, comportamento independente entre os membros da família, desinteresse pelos problemas provocados pela doença e ainda falta de desejo de compartilhar sentimentos. A maneira pelas quais as famílias se adaptam ao câncer é o reflexo do seu relacionamento íntimo, de suas histórias e do seu nível cultural ${ }^{3}$.

Identificamos, através dos dados colhidos, que existe uma parceria na relação mãe-filha na qual a filha se coloca com o elemento de apoio, manifestando características de individuação, mutualidade, flexibilidade, estabilidade, reciprocidade de papéis. Entretanto, quando se trata de uma doença como o câncer, repleta de estigmas e que vem sempre acompanhada da idéia de mor te, percebemos que ela produz em alguns momentos sinais de isolamento e desorganização.
Na época eu entrei em depressão, engordei bastante, mudou tudo, porque a vida ficou sem sentido, a gente não sabe como lidar, como estar ajudando, como passar força para a pessoa quando a situação é grave, porque o câncer não tem cura.

F7

0 grupo familiar apresentou sinais extremos de isolamento do marido cujo padrão fundamental da relação pai-mãe e paifilha parece assentar-se na falta de integração emocional. Por outro lado, essa falta de integração é compensada na relação mãe-filha, com coesão entre elas.

0 diagnóstico de câncer de mama faz emergir a necessidade de ajustamento da família aos tratamentos e suas consequências, demandando várias mudanças nos padrões de interação na família ${ }^{14}$.

Na família 8, composta por três membros: mulher e duas filhas, a mulher com câncer de mama, com 57 anos de idade, separada, completou o ensino médio e trabalhava como técnica de raio $X$. Submeteu-se à cirurgia por câncer de mama, tipo Patey, e à quimioterapia. Estava com cinco anos e um mês de pós-operatório.

Segundo os depoimentos dos familiares, a família, representada pelas duas filhas, retratou-se como um grupo integrado apresentando características familiares saudáveis, como: individuação, mutualidade, flexibilidade, estabilidade e comunicação clara; no entanto, uma das filhas demonstrou reciprocidade de papéis (Quadro 2).

Ela não transparecia estar doente, ela não deixava o sofrimento transparecer. Eu era muito nova, então foi difícil, mas não foi impossível. F8

Identificamos na dinâmica familiar algumas características importantes, como o isolamento das filhas durante o diagnóstico do câncer da mãe, pois na época eram crianças, e a ausência do pai no período de enfrentamento da doença, fatos que geraram limites difusos ou perturbados na relação familiar mãe-pai e pai-filhas.

Perdi um pouco daquela coisa de pai. Não tem chance de continuar a manter laços com alguém que não estava mais aqui e não participava de nada...ele diminuiu até as visitas na época. A gente ficou sozinha..., minha irmã tinha que dormir na casa da minha tia, ele foi nulo. F9

Foi possível verificar que a dinâmica desta família ao longo do processo de adoecer e tratamento revelou todo um movimento no sentido de favorecer o potencial de crescimento entre seus membros à custa de muito esforço da cliente, uma vez que a figura paterna não se fez presente. Esse esforço compensou a ausência paterna e firmou uma aliança mútua e protetora entre mãe e filhas, que acabaram por se posicionar contra o outro par familiar, o pai. 
Na família 9, composta por oito membros: mulher, marido, três filhos e três netos, a mulher com câncer de mama, com 62 anos de idade, não concluiu o ensino fundamental, trabalhou como servente de uma escola de ensino médio e fundamental, é atualmente aposentada. Submeteu-se à cirurgia por câncer de mama, tipo quadrantectomia, à quimioterapia e à radioterapia. Estava com sete anos de pós-operatório.

Diante dos depoimentos do parceiro, da filha e do filho, a família mostrou ser um grupo coeso, manifestando indicações de individuação, mutualidade, flexibilidade e estabilidade (Quadro 2). 0 filho revelou dificuldades para falar sobre o câncer da mãe, mostrando momentos de isolamento na sua interação familiar:

Vou ser sincero com você, eu não procurei me aprofundar muito nesse assunto, quem mais se aprofundou foram as minhas irmãs; faltou aquela intimidade com a mãe...,sempre fui meio fechado, eu fiquei meio por fora da coisa.F9

0 isolamento também foi identificado nos depoimentos da filha, que mostrou sua dificuldade ao vivenciar o câncer de mama no seio familiar.

Eu me desabafava com os amigos que eu tenho, eu jamais queria trazer alguma coisa para dentro de casa. Dentro de casa eu era aquela filha que não tinha problema nenhum..., tentava deixar a casa em ordem..., tem que estar perto dela, forte. F9

A comunicação na família é um fator crítico para o enfrentamento da doença, para o ajuste de papéis, para a satisfação das necessidades de informação, para possibilitar a aproximação entre as pessoas, e há diferentes padrões de comunicação acerca do câncer nas famílias, sendo umas mais abertas e outras mais reticentes ${ }^{17}$.
Alguns trabalhos ${ }^{14,17}$ afirmam que a comunicação tem uma influência significativa no processo de adaptação da família ao câncer.

No entanto, o grupo familiar revelou características capazes de promover o crescimento de seus membros, compensando, assim, os aspectos negativos identificados por eles na dinâmica familiar através de uma rede externa, contando com a participação de amigos e serviços de saúde, como o Rema.

A família 10 era composta por três membros: a mulher e duas filhas, porém no momento morava com ela uma sobrinha e apenas uma filha. A mulher com câncer de mama tinha 48 anos de idade, era separada, não completou o ensino fundamental e trabalha como auxiliar de enfermagem. Submeteu-se à cirurgia por câncer de mama, tipo quadrantectomia, à quimioterapia e à radioterapia. Estava com oito anos e seis meses de pós-operatório.

Os depoimentos dos familiares revelaram, na dinâmica familiar, sinais de individuação, mutualidade, flexibilidade, estabilidade, comunicação clara e reciprocidade de papéis como elementos de apoio à mãe no momento (Quadro 2). Porém, uma das filhas relatou que na ocasião do diagnóstico, há oito anos, ela apresentou comportamentos caracterizados como de isolamento e desorganização, devido a uma série de fatores que interferiram na dinâmica familiar saudável, conforme desvelam os relatos:

Na época do câncer a gente era mais afastada, nós não éramos tão amigas como hoje. Hoje a gente senta, conversa mais do que antes. Eu já tive uma filha, então eu sei o que ela passou comigo. F10

A sobrinha estava morando há pouco tempo na casa e manifestou traços de isolamento e comunicação não clara, no convivio com família. Foi possível verificar que o grupo familiar estava em busca de um clima interpessoal adequado para maior integração e coesão de forma a favorecer o crescimento de cada um.

Quadro 2 - Representação das 10 famílias estudadas de acordo com as dimensões do funcionamento familiar proposto por Barnhill.

\begin{tabular}{|c|c|c|c|c|c|c|c|c|c|c|c|c|c|c|c|c|c|c|c|c|c|c|c|}
\hline \multirow{2}{*}{$\underbrace{\text { Família }}_{\text {Dimensão }}$} & \multicolumn{4}{|c|}{$\begin{array}{c}\text { Família } \\
1\end{array}$} & \multicolumn{2}{|c|}{$\begin{array}{c}\text { Família } \\
2\end{array}$} & \multicolumn{2}{|c|}{\begin{tabular}{|c} 
Família \\
3
\end{tabular}} & \multicolumn{2}{|c|}{$\begin{array}{c}\text { Família } \\
4\end{array}$} & \multicolumn{2}{|c|}{$\begin{array}{c}\text { Família } \\
5\end{array}$} & \multicolumn{2}{|c|}{\begin{tabular}{|c|} 
Família \\
6
\end{tabular}} & \multicolumn{2}{|c|}{\begin{tabular}{|c|} 
Família \\
7
\end{tabular}} & \multicolumn{2}{|c|}{\begin{tabular}{|c} 
Família \\
8
\end{tabular}} & \multicolumn{3}{|c|}{$\begin{array}{c}\text { Família } \\
9\end{array}$} & \multicolumn{2}{|c|}{$\begin{array}{c}\text { Família } \\
10\end{array}$} \\
\hline & $M$ & $\begin{array}{c}\text { Fo } \\
1\end{array}$ & $\begin{array}{c}\text { Fo } \\
2\end{array}$ & $\mathrm{Fa}$ & $\bar{M}$ & Fo & $M$ & $\mathrm{Fa}$ & $M$ & $\mathrm{Fa}$ & Fo & $\mathrm{Ta}$ & $M$ & $\mathrm{Fa}$ & $M$ & $\mathrm{Fa}$ & $\begin{array}{l}\mathrm{Fa} \\
1\end{array}$ & \begin{tabular}{|l|}
$\mathrm{Fa}$ \\
2
\end{tabular} & $M$ & Fo & $\mathrm{Fa}$ & $\mathrm{Fa}$ & $\mathrm{Sa}$ \\
\hline Individuação & $x$ & $x$ & $x$ & $x$ & $x$ & $x$ & - & $x$ & - & $x$ & - & - & $x$ & $x$ & - & $x$ & $x$ & $x$ & $x$ & $x$ & $x$ & $x$ & - \\
\hline Simbiose & $x$ & - & - & - & - & - & - & - & - & - & - & - & - & - & - & - & - & - & - & - & - & - & - \\
\hline Mutualidade & $x$ & $x$ & $x$ & $x$ & $x$ & $x$ & $x$ & $x$ & $x$ & $x$ & $x$ & $x$ & $x$ & $x$ & - & $x$ & $x$ & $x$ & $x$ & $x$ & $x$ & $x$ & - \\
\hline Isolamento & $x$ & $x$ & - & $x$ & $x$ & $x$ & - & $x$ & $x$ & - & $x$ & $x$ & - & - & $x$ & $x$ & $x$ & $x$ & - & $x$ & $x$ & $x$ & $x$ \\
\hline Flexibilidade & $x$ & $x$ & - & - & $x$ & $x$ & $x$ & - & $x$ & $x$ & - & - & $x$ & - & - & $x$ & $x$ & $x$ & $x$ & $x$ & $x$ & $x$ & - \\
\hline Rigidez & - & - & - & - & - & - & $x$ & - & - & - & - & $x$ & - & - & $x$ & - & - & - & - & - & - & $x$ & - \\
\hline Estabilidade & $x$ & - & $x$ & $x$ & $x$ & $x$ & $x$ & - & $x$ & $x$ & $x$ & $x$ & $x$ & $x$ & $x$ & - & $x$ & $x$ & $x$ & $x$ & $x$ & $\mathrm{x}$ & - \\
\hline Desorganização & - & $x$ & $x$ & - & - & - & $x$ & - & - & - & $x$ & - & $x$ & $x$ & $x$ & $x$ & - & - & $x$ & - & - & $x$ & - \\
\hline Com. Clara & $x$ & - & $x$ & $x$ & $x$ & $x$ & - & - & - & - & $x$ & - & $x$ & $x$ & - & - & - & - & $x$ & - & - & $x$ & - \\
\hline Com. Distorcida & - & - & - & $x$ & - & - & $x$ & - & $\mathrm{x}$ & $x$ & $x$ & $x$ & $x$ & $x$ & $x$ & $x$ & - & - & - & - & - & - & $x$ \\
\hline Reciproc. de Papéis & $x$ & $x$ & $x$ & - & $x$ & - & $x$ & - & - & - & - & - & $x$ & - & - & $x$ & - & - & - & - & - & $x$ & - \\
\hline Conflito de Papéis & - & - & - & - & - & - & - & - & - & - & - & - & $x$ & - & - & - & - & - & - & - & - & - & - \\
\hline $\begin{array}{c}\text { Limites claros entre } \\
\text { gerações }\end{array}$ & - & - & - & - & - & - & - & - & - & - & - & - & - & - & - & - & - & - & - & - & - & - & - \\
\hline $\begin{array}{l}\text { Limites difusos } \\
\text { entre gerações }\end{array}$ & - & - & - & - & - & - & - & - & - & - & - & - & - & - & - & $x$ & $x$ & $x$ & - & - & - & - & - \\
\hline
\end{tabular}




\section{CONCLUSÃO}

A análise dos depoimentos sobre a dinâmica familiar dos familiares de mulheres sobreviventes ao câncer de mama permitiu verificar que a avaliação estrutural do funcionamento familiar põe em evidência o vínculo afetivo dos membros entre si e entre os membros externos. Permitiu descrever o contexto vivido por eles no enfrentamento da doença, o qual se reforça na medida em que se identificam características das dimensões familiares, como a mutualidade e a individuação interiorizadas no processo de identidade do grupo familiar. Revelaram que a percepção pelos familiares dos processos de identidade na dinâmica familiar, através da individuação e mutualidade, favoreceu a eles a compreensão da situação e do contexto familiar. Reforçaram ainda que a flexibilização de comportamentos e de condutas entre eles, no ajuste à nova situação, como também a comunicação clara entre todos, e em especial com o familiar acometido pelo câncer de mama, facilitaram a busca de equilíbrio para o funcionamento familiar. Por outro lado, encontramos um grande contingente de maridos que demonstraram sinais de isolamento, e um apresentou sinais de comportamento simbiótico nas dimensões do funcionamento familiar, revelando, portanto, aspectos negativos na relação marital.

De acordo com os achados deste estudo, concordamos com as autoras ${ }^{6}$ quando esclarecem que embora haja regularidade e lógica interna e externa para muitos dos processos de desenvolvimento da família, cada família é diferente, pois cada uma tem seu próprio curso, evolui a partir de várias situações abrangendo a construção familiar do passado e do presente.

\section{REFERÊNCIAS}

1 - Mamede MV. Reabilitação de mastectomizadas: um novo enfoque assistencial [tese]. Ribeirão Preto (SP) Escola de Enfermagem de Ribeirão Preto/USP; 1991.

2 - Freitas AAS, Cabral IE. 0 cuidado à pessoa traqueostomizada: análise de um folheto educativo. Esc Anna Nery Rev Enferm 2008 mar: 12 (1): 84-89.

3 - Ozono $S$ et al. Family functioning and psychological distress among japanese breast cancer patients and families. Supportive Care in Cancer 2005; 13(2): 1044-050.

4 - Bervian PI, Perlini NMOG. A família (con)vivendo com a mulher/ mãe após a mastectomia. Rev Bras Cancerol 2006 ago; 52(2): 12128.

(5) Wernet M. Enfermagem e família investindo no primeiro passo. Rev Bras Enferm 200053 (n.esp): 87-89.

6 - Wright LW. Leahey M. Enfermeiras e famílias: um guia para avaliação e intervenção na família. $3^{\mathrm{a}}$ ed. São Paulo (SP): Roca; 2002.

7 - Barnhill L. Healthy family systems. The Family Coordinator 1979; 22: $94-100$

8 - Bardin L. Análise de conteúdo. $1^{\text {a }}$ ed. Lisboa(P0): Ed 70; 1977.

9 - Cozby PC. Métodos de pesquisa em ciências do comportamento. Tradução de Paula Inez C. Gomide. São Paulo (SP): Atlas; 2003.

10 - Ministério da Saúde (BR). Classificação brasileira de ocupações. $3^{a}$ ed. Brasília (DF); 2002.

11 - Ackerman NW. Diagnóstico e tratamento das relações familiares. $10^{\mathrm{a}}$ ed. Porto Alegre (DF): Artes Médicas; 1986.

12 - Singly F. 0 nascimento do "indivíduo individualizado" e seus efeitos na vida conjugal e familiar. In: Peuxoto CE, Singly F, Cicchelli V,
Os resultados deste estudo revelaram que as formas de sociabilidade existentes entre os integrantes das famílias analisadas se organizaram em relações estruturalmente complementares, porém, como sugere ${ }^{18}$, de natureza distinta.

As relações familiares regulam o fluxo de emoções, facilitando alguns caminhos de liberação emocional e inibindo outros. A configuração familiar controla a qualidade e quantidade de expressão emocional, bem como sua direção. 0 comportamento simbiótico expresso por um dos maridos revelou formas de ação diante de uma percepção de perigo, perigo esse vivenciado por identidades pouco delimitadas ou fundidas como se fossem únicas. A reação de um indivíduo perante a sensação de ameaça como "fuga" é afetada por sentimentos de alienaçãa ${ }^{11}$.

Para os maridos estudados, o funcionamento familiar positivo em situação de crise foi fundamental para a estabilidade não apenas conjugal, mas familiar. A busca desta estabilidade para eles estava condicionada às dimensões positivas dos processos de identidade (individuação e mutualidade) e de adaptação às mudanças, como a flexibilidade, e foi dessa maneira que procuraram facilitar uma nova configuração dos papéis familiares.

Embora a dinâmica familiar tenha sido identificada como positiva no contexto familiar dos estudados, o diagnóstico do câncer de mama gerou dificuldades, mesmo que diferenciadas entre os membros e entre famílias, no funcionamento familiar. Tais dificuldades situaram-se no processamento de informações através da comunicação distorcida e alterações na interação entre os membros, dificultando, assim, o enfrentamento de mudanças, levando muitas vezes ao isolamento e desorganização.

organizadoras. Família e individualização. Rio de Janeiro (RJ): FGV; 2000. p.13- 19.

13 - Biffi RG, Mamede MV. Suporte social na reabilitação da mulher mastectomizada: o papel do parceiro sexual. Rev Esc Enferm USP 2004 set; 38(3): 262- 69.

14 - Billhult A, Segesten K. Strength of motherhood: nonrecurrent breast cancer as experienced by mothers with dependent children. Scandinavian J Caring Sci 2003 Sept; 17(2): 122-28.

15 - Samms MC. The husband's untold account of his wife's breast cancer: a chronologic analysis. Oncol Nurs Forum 1999 Aug; 26(8): 1351-358.

16 - Quintana AM, Santos LHR, Russowsky ILT, Wolff LR. Negação e estigma em pacientes com câncer de mama. Rev Bras Cancerol 1999 out; 45 (4): 45-52.

17 - Kenen R, Ardern-Jones A, Eeles R. We are talking, but are they listening? Communication patterns in families with a history of breast/ ovarian cancer- HBOC. Psychooncol 2004 Aug; 13(5): 335-45.

18 - Romanelli G. Autoridade e poder na família. In: Carvalho MCB, organizadora. A família contemporânea em debate. São Paulo (SP): Cortez; 2003. p.73-88. 